\title{
Choosing drugs for secondary prevention after myocardial infarction: a pragmatic approach
}

\section{Historical perspective}

Early mortality from acute myocardial infarction may be reduced by thrombolytic agents ${ }^{1-4}$ and late mortality following hospital discharge by the use of several oral agents (table 1). ${ }^{5}$ These drugs also reduce morbidity from reinfarction and heart failure. The first drugs shown in large scale clinical trials over a decade ago to be beneficial in the recovery period following acute myocardial infarction were oral anticoagulants. ${ }^{6}$ However, their widespread application was limited by concerns about their safety and by the need to monitor carefully the level of anticoagulation. Historically, $\beta$-adrenoceptor blockers ${ }^{7-9}$ were the next drugs to be shown to be of benefit but again, their use was hindered by concerns over safety in patients with heart failure and their side-effect profile. As a consequence, they are not used as often as they could be. By comparison, low-dose aspirin has been shown to be effective and is well tolerated. ${ }^{5}$ Just recently, two major trials ${ }^{10,11}$ have shown the benefit of angiotensin-converting enzyme (ACE) inhibitors to patients with covert and especially overt heart failure following acute myocardial infarction. Drugs which lower cholesterol levels also appear to reduce reinfarction and mortality. ${ }^{12}$ Class I anti-arrhythmic drugs on the other hand increase mortality as do oral inotropes. ${ }^{13}$ Trials on the effect of Class III anti-arrhythmic drugs are awaited. Calcium antagonist drugs especially dihydropyridines like nifedipine are without benefit in this context, ${ }^{5}$ although verapamil, which also lowers heart rate, may be beneficial in patients without heart failure. ${ }^{14}$ Thus, nearly all cardioactive drugs have been tested for their protective effects in patients following acute myocardial infarction and many have been found to be helpful.

\section{Which drugs should be used for secondary prevention?}

Unfortunately there is little evidence available on the effects of drug combinations for secondary prevention. Are all the individual benefits additive or are the same patients saved by different drugs? Certain combinations seem to be mutually exclusive, eg, $\beta$-adrenoceptor blockers and ACE inhibitors in patients with overt heart failure already taking aspirin and warfarin is a potentially hazardous combination. Data from the SAVE ${ }^{10}$ study which included patients with symptomless left ventricular dysfunction following

Table 1 Drugs shown to reduce mortality following discharge after myocardial infarction (adapted from $^{5}$ )

\begin{tabular}{ll}
\hline Drug & $\%$ Risk reduction $(95 \%$ CI $)$ \\
\hline B-Blockers & $19(27-11)$ \\
Aspirin ${ }^{\star}$ & $17(26-7)$ \\
Anticoagulant & $28(33-10)$ \\
Cholesterol lowering & $14(21-6)$ \\
ACE inhibitors & $27(40-11)$ \\
Verapamil & $22(38-1)$ \\
\hline
\end{tabular}

*Does not include data since 1979 acute myocardial infarction, in which $35 \%$ of patients were taking $\beta$-adrenoceptor blockers and $59 \%$ aspirin before randomisation to captopril or placebo shows that there is additional benefit from adding an ACE inhibitor to existing secondary prevention therapy in carefully selected patients. But if every patient were given every drug known to reduce mortality after myocardial infarction (see table 1) they could be taking five or six different preparations! So which drug should be given to which patient?

\section{A pragmatic approach}

The available data lend themselves to a pragmatic approach. The most widely prescribed drug for secondary prevention is aspirin. In the low dosage $(150-300 \mathrm{mg})$ used in this context few patients have contra-indications, few suffer serious side effects and the drug is cheap and effective. All patients should therefore be given aspirin following acute myocardial infarction unless there are specific contra-indications, eg, allergy or known intolerance. Aspirin works by reducing platelet activation and probably exerts its anti-ischaemic effect by modifying the natural history of coronary thrombosis.

\section{What other drugs with aspirin?}

If a combination of drugs were to be used then it would be reasonable to chose another drug which exerted its effect in a different way. Certain lipid-soluble $\beta$-adrenoceptor blocking drugs have proven benefits in patients after myocardial infarction and although contra-indicated in patients with overt heart failure, are often tolerated well by patients with left ventricular damage who are symptomless. ${ }^{10}$ Indeed, patients with mild heart failure appeared of benefit most from the treatment. ${ }^{9}$ Echocardiographic data ${ }^{15,16}$ show that ACE inhibitors reduce left ventricular dilatation which occurs progressively following anterior myocardial infarction, and this is thought to be a precursor of left ventricular failure. In patients with overt heart failure the benefits of ACE inhibitors are now established. They improve symptoms, slow the rate of left ventricular deterioration, and improve short-term mortality. ${ }^{17}$ In patients with asthma and no heart failure in whom $\beta$ adrenoceptor blockers are contra-indicated, verapamil ${ }^{13}$ could be used.

Oral anticoagulants are indicated for patients with atrial fibrillation, left ventricular aneurysms, and patients with severe congestive cardiac failure. Recent evidence suggests that lowering serum cholesterol by simvastatin in patients with previous infarction or angina with serum cholesterol in the range $5.5-8.0 \mathrm{mmol} / 1$ who were already on a lipid-lowering diet also reduces subsequent cardiovascular events and total mortality. The algorithm (figure) provides a decision route for the choice of $\operatorname{drug}(\mathrm{s})$ for secondary prevention.

\section{Conclusion}

A simple approach to secondary prevention is therefore to give all patients aspirin and other drugs using clinical 


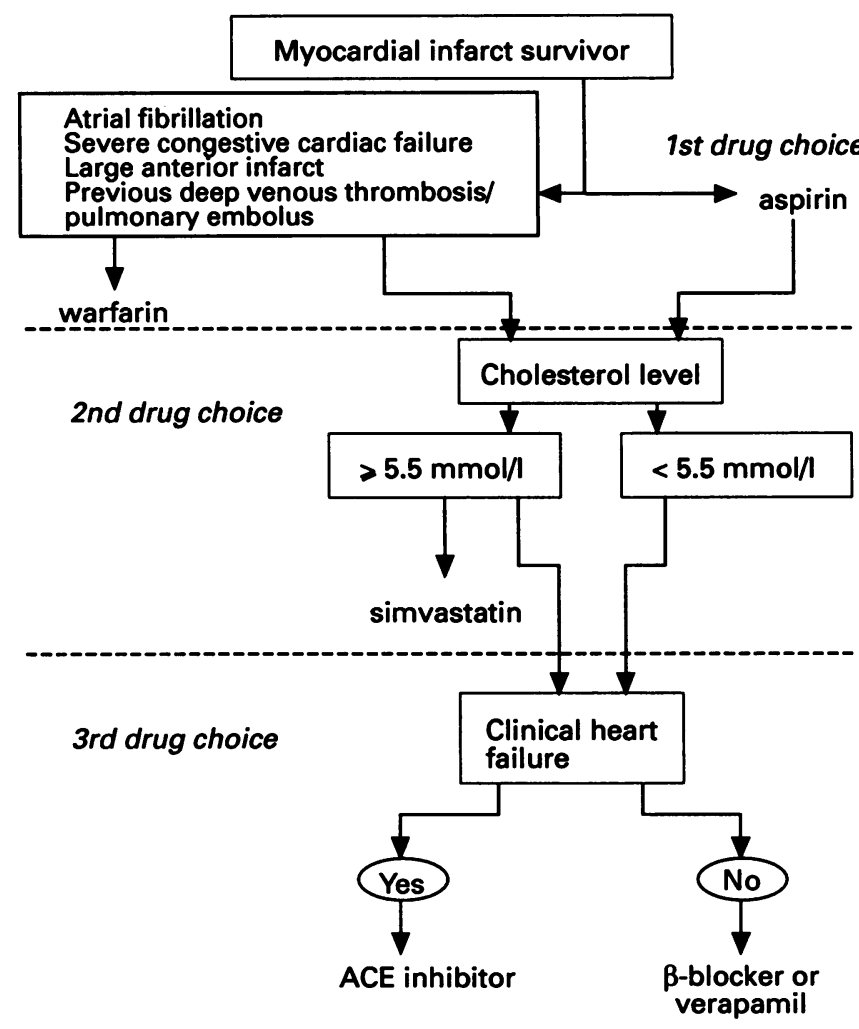

Figure For choice of drugs for secondary prevention after myocardial infarction

\begin{tabular}{|l|}
\hline Learning points \\
\hline - drugs for secondary prevention following infarction save \\
lives \\
- choice of drug is influenced by clinical factors \\
\hline
\end{tabular}

1 Gruppo Italiano per lo Studio della Streptochinasi nell'Infarto Miocardico (GISSI). Effectiveness of intravenous thrombolytic treatment in acute myocardial infarction. Lancet 1986; i: 397-401.

2 AIMS Trial Study Group. Effect of intravenous APSAC on mortality after acute myocardial infarction: preliminary report of a placebo controlled trial. Lancet 1988; i: 545-9.

3 ISIS-2 (Second International Study of Infarct Survival) Collaborative Group. Randomised trial of intravenous streptokinase, oral aspirin, both, or neither among 17,187 cases of suspected acute myocardial infarction: SIS-2. Lancet 1988; ii: 349-60.

4 Wilcox RG, von der Lippe G, Olsson CG, Jensen G, Skene AM, Hampton J. Trial of tissue plasminogen activator for mortality reduction in acute myocardial infarction: Anglo-Scandinavian Study of Early Thrombolysi (ASSET). Lancet 1989; ii: 525-30.

5 Lau J, Antman EM, Jimenez-Silva J, et al. Cumulative meta-analysis of therapeutic trials for myocardial infarction. $N$ Engl $\mathcal{f}$ Med 1992; 327: 248-54.

6 Sixty-Plus Reinfarction Study Research Group. A double blind trial to assess long term oral anticoagulation therapy in elderly patients after myocardial infarction. Lancet 1980; ii: 989-94

7 Norwegian Multicenter Study Group. Timolol-induced reduction in mortality and reinfarction in patients surviving acute myocardial infarction. $N$ Engl $\Im$ Med 1981; 304: 801-7.

8 Hjalmarson A, Elmfeldt D, Herlitz J, et al. Effect on mortality of metoprolol in acute myocardial infarction. A double blind randomised trial. Lancet 1981;

9 Beta-Blocker Heart Attack Trial Research Group. A randomised trial of propranolol in patients with acute myocardial infarction. I Mortality results. fAMA 1982; 247: 1707-14.
Table 2 Criteria for choice of secondary preventive agent

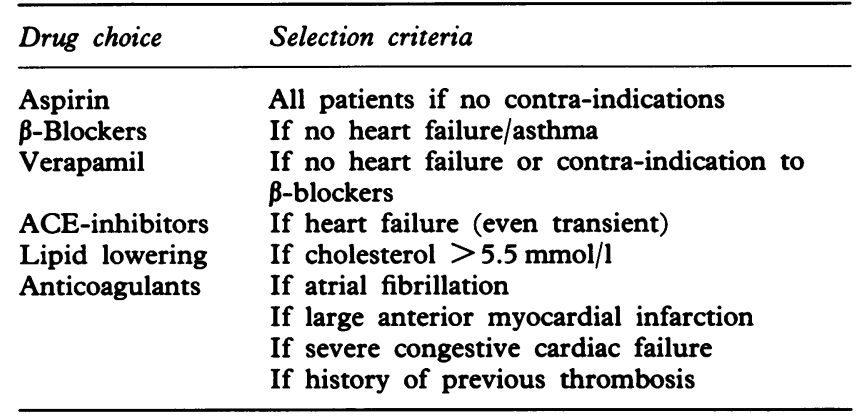

parameters to influence the choice (table 2; figure). If it is intended to treat patients with symptomless left ventricular dysfunction, radionuclide scanning as used in the SAVE study is required to identify them. The approach described here, however, uses clinical parameters only and restricts the number of drugs prescribed to two in most instances. It must be remembered that the aim of cardiac rehabilitation is to return patients to living as near a normal life as possible. The need to take medication routinely reinforces the sick role and may be psychologically disadvantageous. Whether this approach is right or wrong, just thinking about the question is likely to lead to the prescription of more secondary prevention, with resultant tangible benefits on cardiovascular mortality. ${ }^{18}$

KEVIN S CHANNER Cardiology Department, Royal Hallamshire Hospital, Sheffield S10 2fF, UK

10 Pfeffer MA, Braunwald E, Moye LA, et al. Effect of captopril on mortality and morbidity in patients with left ventricular dysfunction after myocardial infarction. Results of the survival and ventricular enlargement trial. The infarction. Results of the survival and ventricular enlargen
SAVE Investigators. $N$ Engl $f$ Med 1992; 327: 669-77.

11 The Acute Infarction Ramipril Efficacy (AIRE) Study Investigators. Effect of ramipril on mortality and morbidity of survivors of acute myocardial infarction with clinical evidence of heart failure. Lancet 1993; 342: 821-8.

12 Scandinavian Simvastatin Survival Study Group. Randomised trial of cholesterol lowering in 4444 patients with coronary heart disease: the cholesterol lowering in 4444 patients with coronary heart disease: the
Sandinavian Simvastatin Survival Study (4S). Lancet 1994; 344: 1383-9. 3 Cowley AJ, Skene AM. Treatment of severe heart failure: quantity or quality of life? A trial of enoximone. Br Heart $\mathcal{F} 1994 ; 72: 226-30$.

14 The Danish Study Group on verapamil in myocardial infarction. Effect of verapamil on mortality and major events after acute myocardial infarction (The Danish Verapamil Infarction Trial II -DAVIT II). Am $\mathcal{~}$ Cardiol 1990; 66: 779-85.

15 Pfeffer MA, Lamas GA, Vaughan DE, Parisi AF, Braunwald E. Effect of captopril on progressive left ventricular dilatation after anterior myocardial infarction. $N$ Engl $f$ Med 1988; 319: 80-6.

16 Sharp N, Murphy J, Smith H, Hannan S. Treatment of patients with symptomless left ventricular dysfunction after myocardial infarction. Lancet 1988; 1: 255-9.

17 The CONSENSUS trial study group. Effects of enalapril on mortality in severe congestive heart failure: results of the Cooperative North Scandinavian Enalapril Survival Study (CONSENSUS). $N$ Engl $\Im$ Med 1987; 316: $1429-35$.

18 Smith J, Channer KS. Increasing the prescription of drugs for secondary prevention following acute myocardial infarction. Clin Sci 1995 (in press). 